\title{
AS INFLUÊNCIAS DO MARKETING PROMOCIONAL NA TOMADA DE DECISÃO DE COMPRAS DO CONSUMIDOR: UMA ANÁLISE QUANTITATIVA
}

\author{
Raphaela Pereira Rangel (UFRRJ) rangelufrrj@hotmail.com \\ Gustavo Lopes Olivares (UFRRJ) olivares.rural@gmail.com.br
}

\section{Resumo}

O mundo globalizado dos negócios tem como característica a pressão por mudanças. A cada instante surgem novos modelos e novas práticas de gestão que levam a organização a desenvolver habilidades, não só de reagir, mas sim de prever mudanças. Dentro dos processos organizacionais, o marketing desempenha um papel fundamental, permitindo o monitoramento do ambiente externo e disponibilizando um conjunto de ferramentas para que essas empresas formulem suas estratégias e alcancem seus objetivos. Uma dessas ferramentas é o monitoramento dos movimentos dos consumidores em termos de necessidades e desejos. Neste contexto, o objetivo deste trabalho é avaliar as influências das promoções sob a decisão de escolha do consumidor e se esse, configura-se como um recurso eficiente para a empresa acompanhar o dinamismo característico da contemporaneidade. Para esse fim, utilizou-se um questionário virtual disparado através do Google Forms, alcançando uma amostra de 37 participantes. Os dados foram tabulados pelo software de estatística SPSS e os resultados mostraram que, mais de $80 \%$ da amostra consome produtos influenciados por algum tipo de promoção. Dessa forma, a pesquisa contribuiu tanto para ratificar teorias de marketing, quanto para a melhoria das práticas de gestão.

Palavras-Chave: Gestão, marketing promocional, comportamento do consumidor.

\section{Introdução}

As organizações contemporâneas experimental os efeitos das mudanças ambientais e a intensidade imposta por elas. Consumidores cada vez mais exigentes, o ciclo de vida de produtos e serviços, serviços mais curtos e avanços constantes da tecnologia da informação e da comunicação. Essa intensidade impacta diretamente nos hábitos, comportamentos, necessidades e desejos dos consumidores em potencial de quase todos os nichos de mercado.

Dentro desse cenário, produzir, comunicar, vender e entregar eficientemente seus produtos e serviços, não é mais uma opção e sim um requisito que mantém a competitividade do negócio. Desta forma, o Marketing tem como objetivo satisfazer as necessidades e os desejos de seus 
clientes, considerando que esses podem não ter a consciência de suas motivações e assim, responder a determinadas influências que o façam mudar de ideia a qualquer momento (KOTLER, 2012).

A partir dessa definição de marketing surge um outro conceito que forma a premissa fundamental para esta pesquisa, o Comportamento do Consumidor. De acordo com Solomon (2002), o comportamento do consumidor é o processo pelo qual o indivíduo ou grupos, selecionam, compram, usam ou dispõe de produtos, serviços, ideias ou experiências para satisfazer necessidades e desejos. Entender o porquê e a forma pela qual os clientes efetuam suas compras é fundamental para que uma empresa consiga atingir seus objetivos mercadológicos e mantenha um atendimento satisfatório, visto que, existem diversos grupos de consumidores e cada qual com seus motivos de compra (LAS CASAS, 2005).

A decisão de compra do consumidor inicia-se com o reconhecimento de uma necessidade ou desejo, que pode surgir de uma sensação interna ou de estímulos externos, como atividades promocionais. A motivação vem do impulso interior ao consumidor perceber que tem uma necessidade (CHURCHILL;PETTER, 2003). Enquanto, que a necessidade é uma espécie de satisfação básica do ser humano, os desejos são carências por satisfações específicas moldados por forças e instituições sociais (KOTLER, 2006).

Neste contento, o objetivo principal desse estudo recai na identificação das influências do marketing promocional no processo de tomada de decisão de compras dos consumidores.

\section{Fundamentação teórica}

\subsection{Comunicação integrada de marketing (CIM)}

Dias (2003) define a Comunicação Integrada de Marketing (CIM) como o resultado de reconhecer que a comunicação de marketing só poderá ser eficaz e alcançar seus objetivos, se todos os "elementos do programa de comunicação forem coordenados e integrados", ao ponto de criar uma mensagem única, diferente e consistente para o consumidor final daquele produto ou serviço.

Para Crescitelli e Figueiredo (2011), devido ao atual excesso de informação, não é fácil estabelecer um comunicado aos seus clientes. Por conseguinte, as organizações procuram empregar diferentes estratégias ao mesmo tempo. Na presença de diferentes formas, surgiu o desafio de agrupar tantas informações em uma só mensagem exclusiva, através da CIM. Esse 
pensamento, de acordo com Lucas e Souza (2011), passou a abranger também transações de negócios e não somente os meios de comunicação, resultando em "tentativas de olhar o cliente" como um ponto de partida para concepção de uma "rede" de comunicação para a empresa (ZUCO;REIS, 2010).

Sendo Assim, Santos, Ferreira e Paixão (2017), esclarecem que a CIM, tem como objetivo remeter ao público uma única e efetiva mensagem através de uma integração das ferramentas de comunicação, sendo responsável por criar um "elo perene" entre a organização e seus clientes, reforçar sua imagem no mercado, ter como iniciativa desenvolver uma estratégia exata de comunicação (OGDEN;CRESCITELLI, 2007), e possuir uma função construtiva diante de empresas que carecem destacar a sua marca no mercado globalizado (OLIVEIRA;SERRALVO; JOÃO; FURLANI, 2015).

\subsection{Marketing promocional}

Segundo a Associação de Maketing Promocional (2017), o Marketing Promocional pode ser definido como a comunicação com objetivo de "incrementar a percepção de valor" através das suas técnicas promocionais e contatos com os clientes que "ativem" a compra, como a fidelização ou a experiência com produtos e serviços (AMPRO, 2017). Ainda, conforme a AMPRO (2017), o marketing promocional pode ser divido em distribuição e apresentação do produto/serviço, sendo as principais estratégias promocionais: ofertas monetárias e não monetárias, distribuição de prêmios e brindes, eventos promocionais e incentivos.

Ter uma boa estratégia de Marketing Promocional aumenta consideravelmente as chances de conquistar novos clientes e convertê-los em consumidores fiéis. Segundo Kotler e Armstrong (2001), os incentivos de curto prazo servem como encorajamento de uma compra ou venda, cabendo ressaltar que grande parte das ofertas promocionais tem como objetivo influenciar a compra imediata.

\section{Procedimentos metodológicos}

Nesta seção apresenta-se os procedimentos metodológicos utilizados para alcançar os objetivos da pesquisa.

Conforme Vergara (2007), a pesquisa quanto à sua finalidade, pode ser classificado como descritivo porque possui características de pesquisa de opinião e essa, quanto aos fins, se insere na classificação de pesquisa descritiva. Vergara (2007), classifica a pesquisa quanto aos 
meios de investigação, nesse sentido, o presente trabalho se caracteriza como uma pesquisa de campo, bibliográfica e documental.

\subsection{Coleta de dados}

Para coletar os dados necessários para a pesquisa, utilizou-se como instrumento um questionário virtual disponibilizado via Google Forms distribuídos para 50 (cinquenta) pessoas, em que 37 (trinta e sete) retornaram com 100\% das respostas, configurando-se como a amostra da pesquisa.

O questionário dividiu-se em duas partes: a primeira com variáveis referentes aos fatores socioeconômicos e a segunda parte relaciona diretamente com o objetivo do estudo, a influência da promoção no consumo.

\subsection{Tratamento dos dados}

Como ferramenta quantitativa para o tratamento dos dados, recorreu-se ao SPSS (Statistical Package for Social Sciences) que é um dos softwares mais utilizados para análises estatísticas. O SPSS auxiliou na tabulação dos dados e na geração das tabelas e gráficos. Pelas características da pesquisa as variáveis utilizadas pelo questionário são em sua maioria qualitativas nominais e ordinais.

Após a inserção dos dados, foram analisados questão por questão, buscando interpretar as variáveis nominais pela frequência e pelo percentual e as variáveis ordinais através da moda e da média.

\section{Análise dos dados}

Nesta seção apresenta-se a tabulação dos dados obtidos pela aplicação dos questionários divido em dividido em duas partes: variáveis socioeconômicas e variáveis de marketing.

\subsection{Variáveis socioeconômicas}

Nesta seção apresenta-se a tabulação dos dados obtidos pela aplicação dos questionários divido em dividido em duas partes: variáveis socioeconômicas e variáveis de marketing.

A primeira questão trata-se da idade dos entrevistados, conforme apresentando na Tabela $1 \mathrm{e}$ no Gráfico 1, 54,1\% da amostra são pessoas com idade entre 26 e 35 anos e 24,3\% são pessoas entre 18 e 25 anos. Assim, destaca-se que 78,4\% dos indivíduos são jovens adultos 
entre 18 e 35 anos de idade, um perfil de consumidor importante para maioria dos produtos e serviços disponibilizados no mercado.

Tabela 1 - Idade dos entrevistados

\begin{tabular}{|l|r|r|r|r|}
\hline & Frequência & Porcentagem & $\begin{array}{c}\text { Porcentagem } \\
\text { válida }\end{array}$ & $\begin{array}{c}\text { Porcentagem } \\
\text { acumulativa }\end{array}$ \\
\hline 26 a 35 anos & 20 & 54,1 & 54,1 & 54,1 \\
\hline & & & & 78,4 \\
18 a 25 anos & 9 & 24,3 & 24,3 & 91,9 \\
36 a 45 anos & 5 & 13,5 & 13,5 & 97,3 \\
46 a 50 anos & 2 & 5,4 & 5,4 & 100,0 \\
Acima de 50 anos & 1 & 2,7 & 2,7 & 100,0 \\
Total & 37 & 100,0 & & \\
\hline
\end{tabular}

Fonte: Elaborado pela autora

Gráfico 1 - Distribuição percentual das idades dos entrevistados

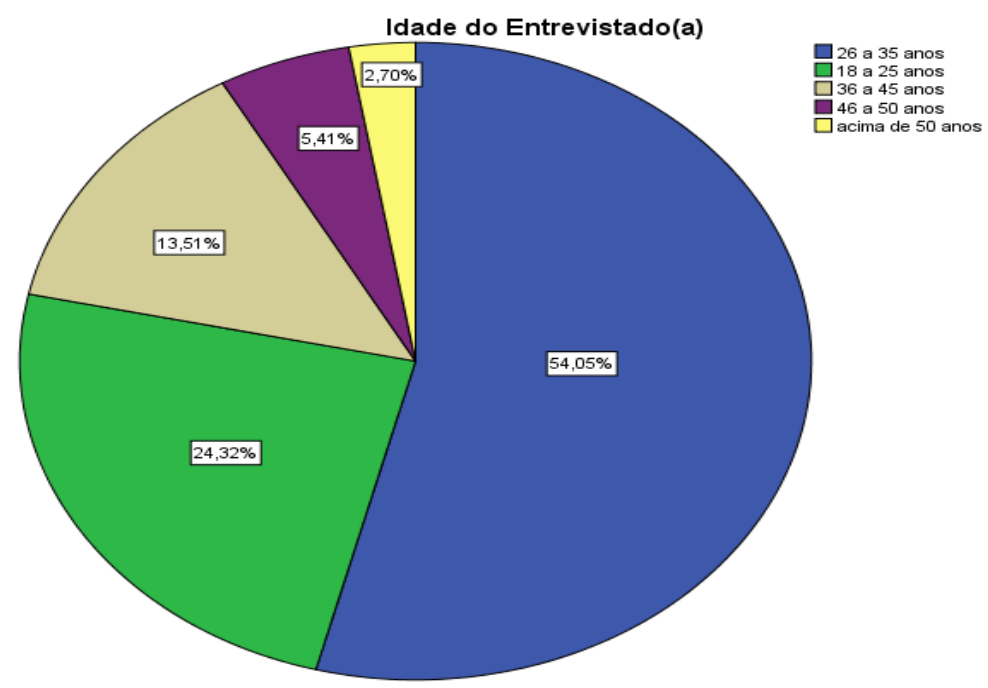

A Questão 2 buscou identificar o gênero da amostra coletada. A maioria dos entrevistados (as), são do sexo feminino com 62,2\% e, 37, $8 \%$ do sexo masculino. A Tabela 2 e o Gráfico 2 mostram esses dados que também permitem caracterizar um perfil de consumidor com especificidades para determinados produtos e serviços. 
Tabela 2 - Sexo dos entrevistados

\begin{tabular}{|rl|r|r|r|r|}
\hline & & & \multicolumn{2}{|c|}{$\begin{array}{c}\text { Porcentagem } \\
\text { válida }\end{array}$} & $\begin{array}{c}\text { Porcentagem } \\
\text { acumulativa }\end{array}$ \\
\hline Válido & Frequência & Porcentagem & 62,2 & 62,2 \\
& Masculino & 23 & 62,2 & 37,8 & 100,0 \\
& 14 & 37,8 & 100,0 & \\
\hline
\end{tabular}

Fonte: Elaborado pela autora

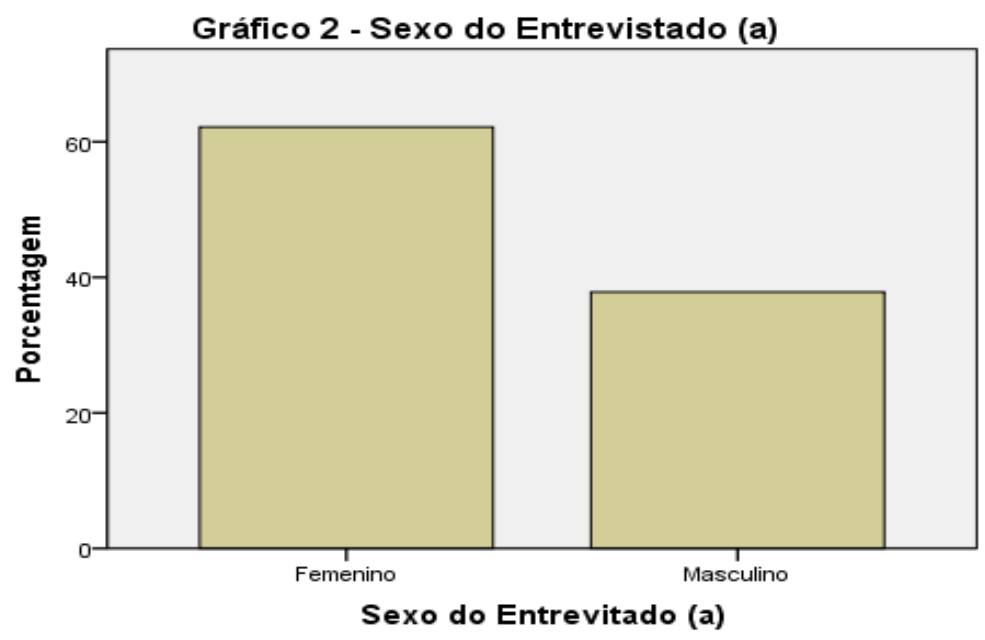

As questões 3 e 4, respectivamente, investigaram o estado civil e a existência de filhos, pois no contexto do marketing promocional o estágio de vida do consumidor retrata suas preferências na compra de um produto/serviço.

Tabela 3 - Estado civil dos entrevistados

\begin{tabular}{|c|c|c|c|c|c|}
\hline & & Frequência & Porcentagem & $\begin{array}{c}\text { Porcentagem } \\
\text { válida }\end{array}$ & $\begin{array}{l}\text { Porcentagem } \\
\text { acumulativa }\end{array}$ \\
\hline \multirow[t]{5}{*}{ Válido } & Solteiro & 28 & 75,7 & 75,7 & 75,7 \\
\hline & Casado & 5 & 13,5 & 13,5 & 89,2 \\
\hline & Outro & 3 & 8,1 & 8,1 & 97,3 \\
\hline & Separado & 1 & 2,7 & 2,7 & 100,0 \\
\hline & Total & 37 & 100,0 & 100,0 & \\
\hline
\end{tabular}

Fonte: Elaborado pela autora 


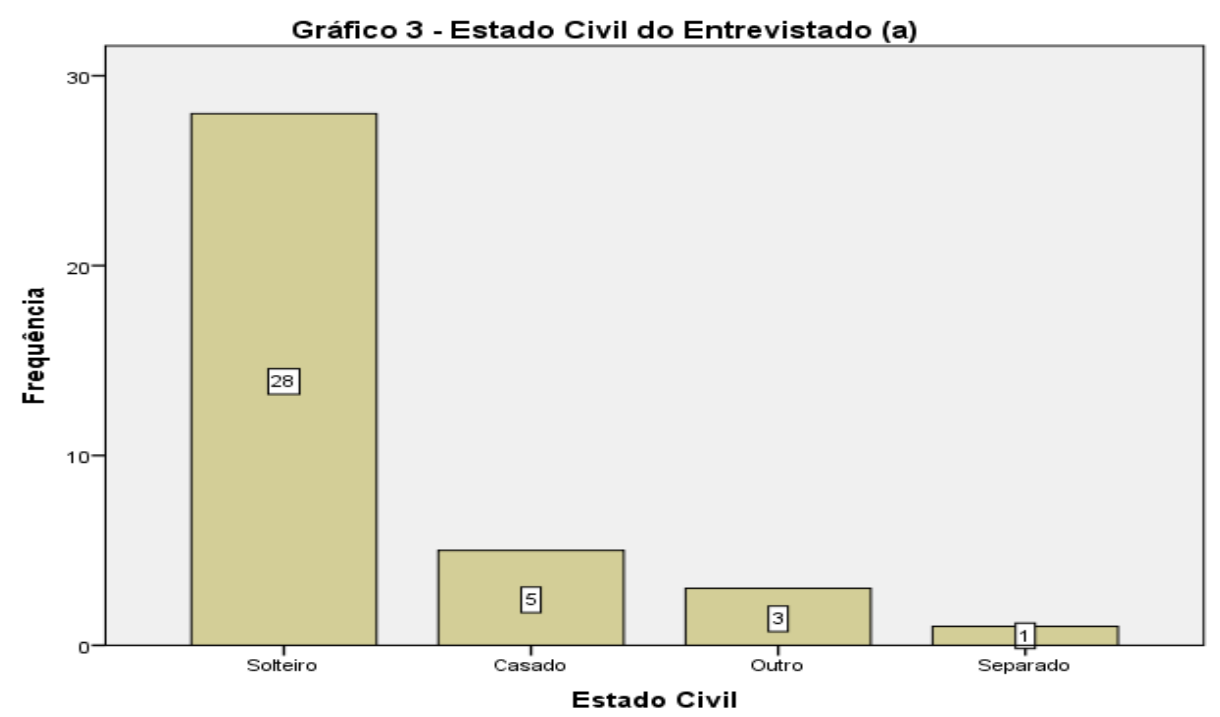

Tabela 4 - Existência de filhos dos entrevistados

\begin{tabular}{|rl|r|r|r|r|}
\hline & & & \multicolumn{2}{|c|}{$\begin{array}{c}\text { Porcentagem } \\
\text { válida }\end{array}$} & $\begin{array}{c}\text { Porcentagem } \\
\text { acumulativa }\end{array}$ \\
\hline Válido & Não & 30 & 81,1 & 81,1 & 81,1 \\
& Sim & 7 & 18,9 & 18,9 & 100,0 \\
& Total & 37 & 100,0 & 100,0 & \\
\hline
\end{tabular}

Fonte: Elaborado pela autora

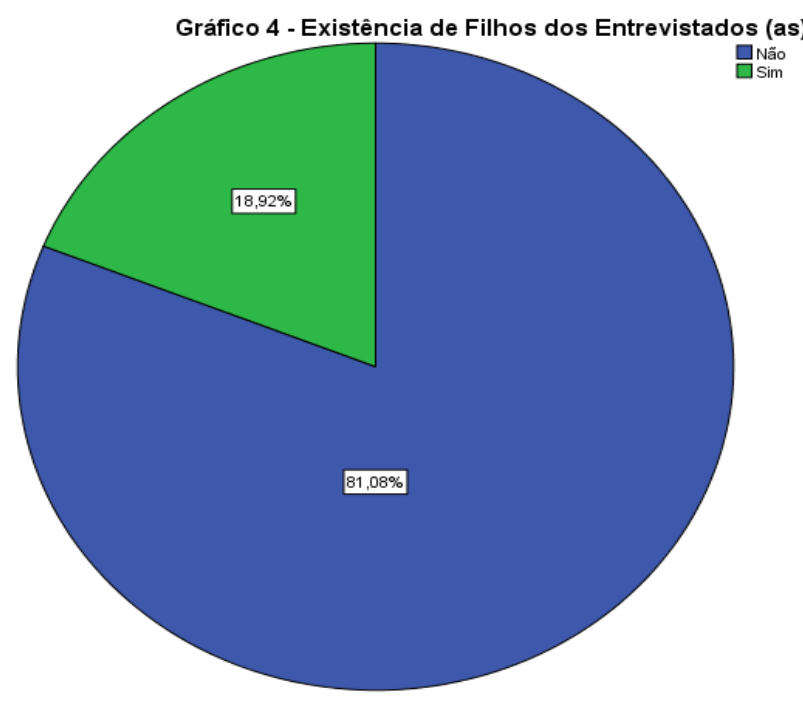


Pode-se inferir, então que, mais de $75 \%$ dos entrevistados são solteiros e mais de $81 \%$ não possuem filhos, configurando-se um extrato de consumidores que, provavelmente, utilizam suas rendas para consumo próprio em vez de destiná-los aos seus filhos.

O próximo questionamento (Questão 5) diz respeito ao grau de instrução dos entrevistados. Como pode ser visto na Tabela 5, 22 dos 37 participantes da amostra, perfazendo um total de $59,5 \%$ possuem nível superior, enquanto $29,7 \%$ tem pós-graduação e apenas $10,8 \%$ com ensino médio completo.

Tabela 5 - Nível de escolaridade dos entrevistados

\begin{tabular}{|ll|r|r|r|r|}
\hline & & & $\begin{array}{c}\text { Porcentagem } \\
\text { válida }\end{array}$ & $\begin{array}{c}\text { Porcentagem } \\
\text { acumulativa }\end{array}$ \\
\hline Válido & Frequência & Porcentagem & 59,5 & 59,5 & 59,5 \\
& 22 & 29,7 & 29,7 & 89,2 \\
& Pós-Graduação & 11 & 10,8 & 10,8 & 100,0 \\
Médio & 4 & 100,0 & 100,0 & \\
Total & 37 & & \\
\hline
\end{tabular}

Fonte: Elaborado pela autora

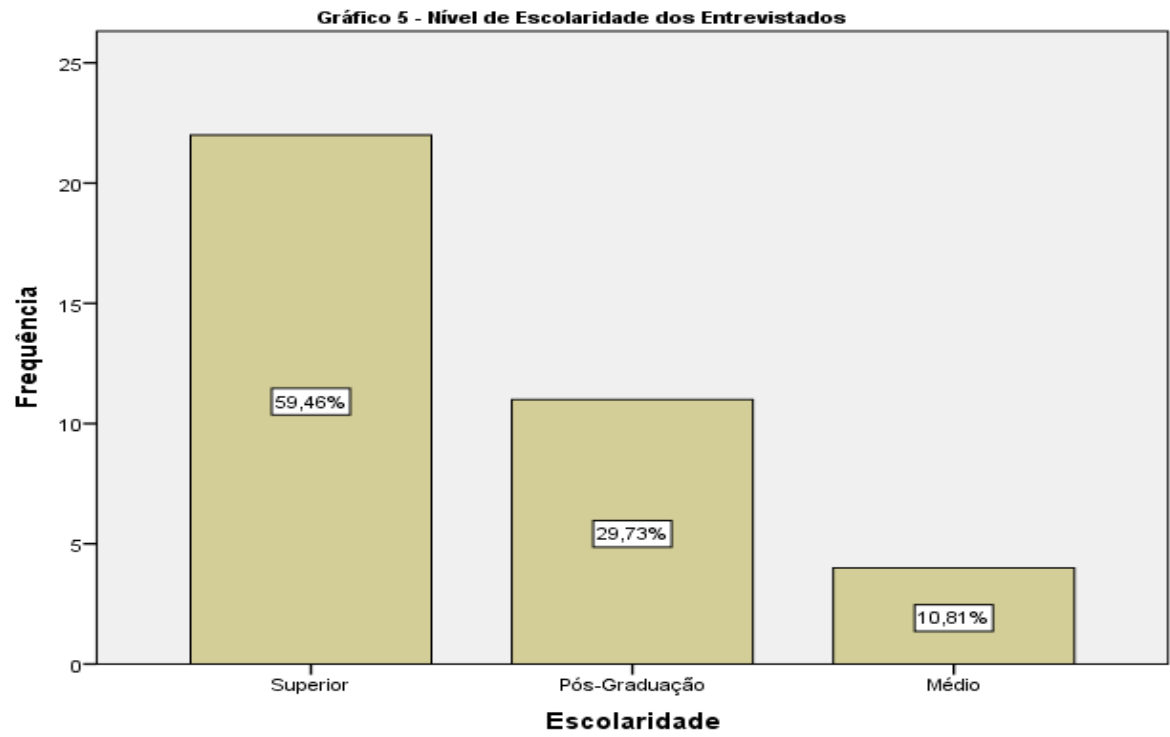

A Questão 6 do questionário buscou identificar se o entrevistado tem emprego (Tabela 6 e Gráfico 6) e em caso afirmativo, a Questão 7, complementarmente, verificou em qual setor da economia a atuação dos participantes (Tabela 7 e Gráfico 7). 
Tabela 6 - O entrevistado trabalha atualmente

\begin{tabular}{|rr|r|r|r|r|}
\hline & & & $\begin{array}{r}\text { Porcentagem } \\
\text { válida }\end{array}$ & $\begin{array}{r}\text { Porcentagem } \\
\text { acumulativa }\end{array}$ \\
\hline \multirow{2}{*}{ Válido } & Frequência & Porcentagem & 78,4 & 78,4 \\
& Sim & 29 & 78,4 & 21,6 & 100,0 \\
& Não & 8 & 21,6 & 100,0 & \\
& Total & 100,0 & \\
\hline
\end{tabular}

Fonte: Fonte: Elaborado pela autora.

Tabela 7 - Setor de atuação profissional dos entrevistados

\begin{tabular}{|c|c|c|c|c|c|}
\hline & & Frequência & Porcentagem & $\begin{array}{l}\text { Porcentagem } \\
\text { válida }\end{array}$ & $\begin{array}{l}\text { Porcentagem } \\
\text { acumulativa }\end{array}$ \\
\hline \multirow[t]{4}{*}{ Válido } & Serviço & 25 & 67,6 & 67,6 & 67,6 \\
\hline & Outro & 9 & 24,3 & 24,3 & 91,9 \\
\hline & Indústria & 3 & 8,1 & 8,1 & 100,0 \\
\hline & Total & 37 & 100,0 & 100,0 & \\
\hline
\end{tabular}

Fonte: Elaborado pela autora.

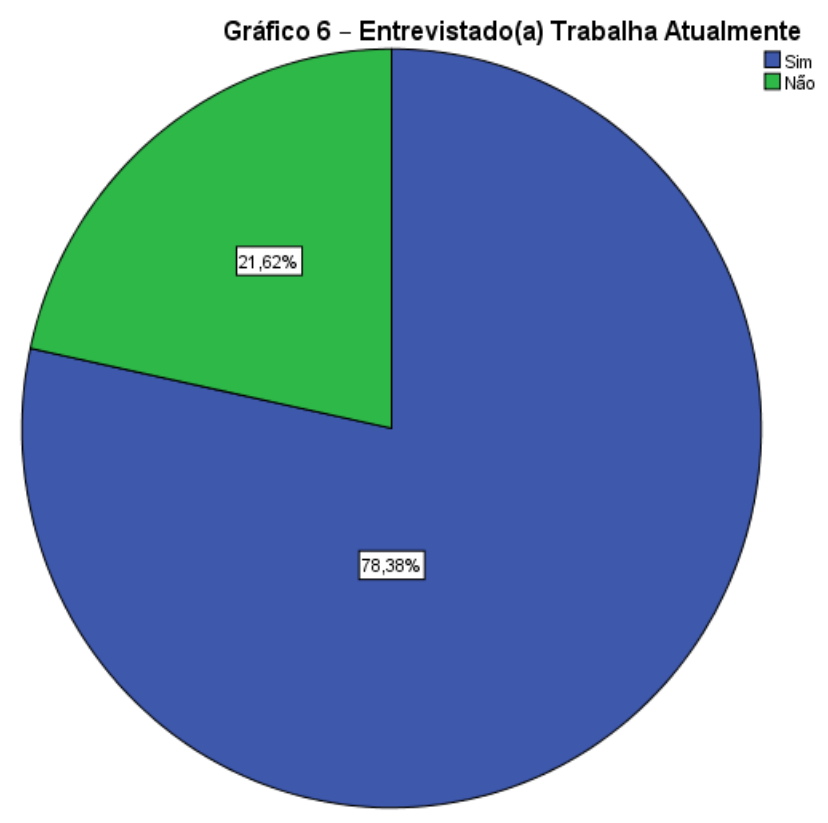




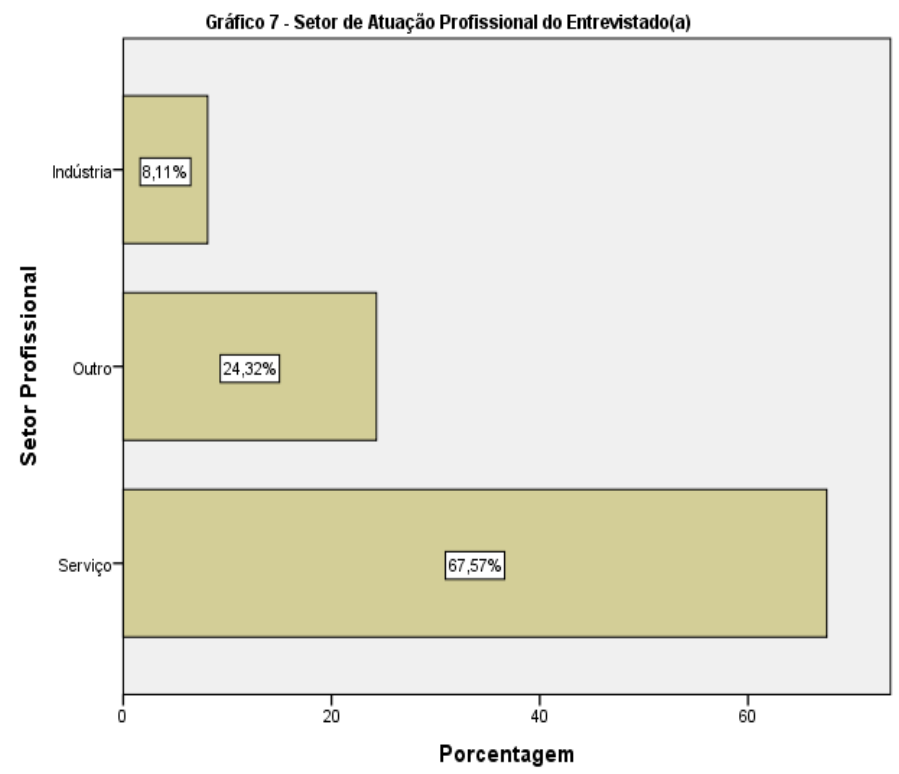

Conforme visto nas Tabelas 6 e7, 78,4\% executam atividades remuneradas. Não se preocupou em investigar se a atividade era fixa ou temporária, pois para pesquisa o relevante é identificar se os entrevistados possuem renda por meios próprios, podendo ter mais autonomia na decisão de compra. Daqueles que trabalham, 67,6\% atuam no setor de serviços, $8,1 \%$ na indústria e $0 \%$ no setor de comércio o que retrata uma situação inusitada. Os Gráficos 6 e 7 sintetizam dados sobre emprego e setor de atuação profissional.

Por fim, encerrando a parte socioeconômica, a $8^{\mathrm{a}}$ questão identificou a faixa de renda familiar, mostrados na Tabela 8 e Gráfico8.

Tabela 8 - Renda familiar dos entrevistados

\begin{tabular}{|c|c|c|c|c|c|}
\hline & & Frequência & Porcentagem & $\begin{array}{l}\text { Porcentagem } \\
\text { válida }\end{array}$ & $\begin{array}{l}\text { Porcentagem } \\
\text { acumulativa }\end{array}$ \\
\hline \multirow[t]{5}{*}{ Válido } & Até um salário mínimo & 1 & 2,7 & 2,7 & 2,7 \\
\hline & 1 a 3 salários mínimos & 13 & 35,1 & 35,1 & 37,8 \\
\hline & 4 a 10 salários mínimos & 20 & 54,1 & 54,1 & 91,9 \\
\hline & $\begin{array}{l}\text { Acima de } 10 \text { salários } \\
\text { mínimos }\end{array}$ & 3 & 8,1 & 8,1 & 100,0 \\
\hline & Total & 37 & 100,0 & 100,0 & \\
\hline
\end{tabular}

Fonte: Elaborado pela autora

A amostra é caracterizada por participantes que tem renda entre 4 e 10 salários mínimos com 54, $1 \%$ do total, seguindo por participantes que apresentem renda entre 1 e 3 salários mínimos 
com $35,1 \%$ do total. Esses dados são relevantes à medida que definem que tipo de produto ou serviço podem consumir.

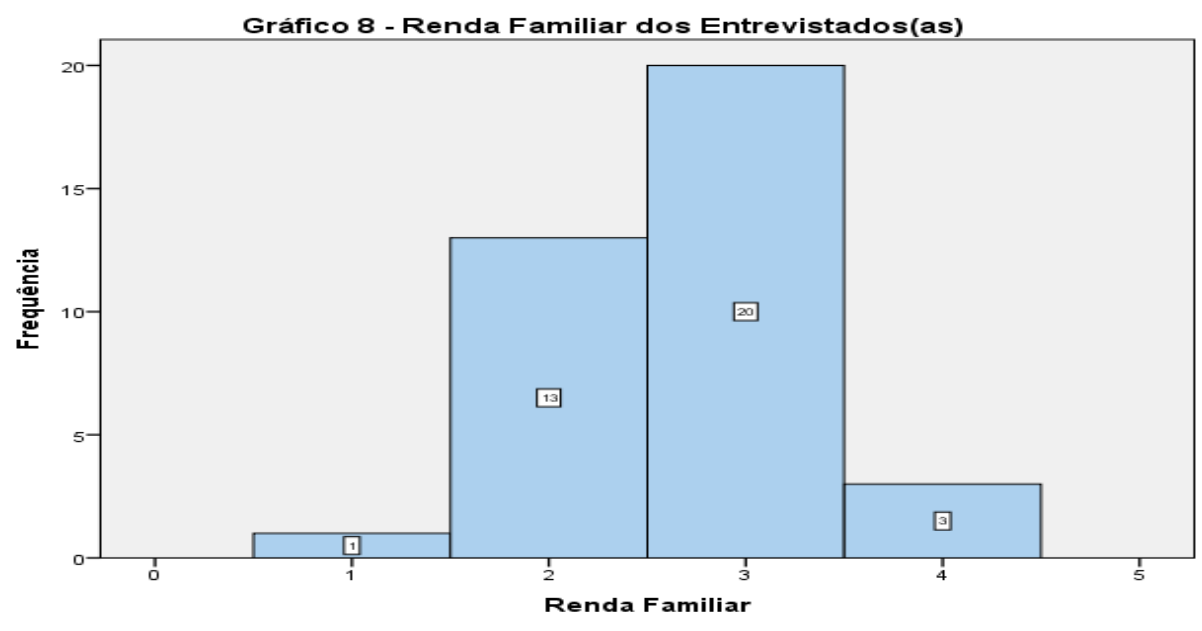

A seguir, analisam-se os dados referentes às variáveis de marketing, configurando-se a segunda parte da análise do questionário.

\subsection{Variáveis de marketing}

A Questão 9 buscou conhecer qual o meio prioritário de acesso a informação por parte dos entrevistados, estratégico para de marketing, pois as propagandas guardam uma relação muito próxima e são definidas a partir da mídia mais utilizada. A Tabela 9 e o Gráfico 9 mostram os dados referentes a questão.

Tabela 9 - Meios de acesso à informação dos entrevistados

\begin{tabular}{|rl|r|r|r|r|}
\hline & & & \multicolumn{2}{|c|}{$\begin{array}{c}\text { Porcentagem } \\
\text { válida }\end{array}$} & $\begin{array}{c}\text { Porcentagem } \\
\text { acumulativa }\end{array}$ \\
\hline \multirow{2}{*}{ Válido } & Frequência & Porcentagem & 45,9 & 45,9 & 45,9 \\
& TV & 17 & 54,1 & 54,1 & 100,0 \\
& Internet & 20 & 100,0 & 100,0 & \\
Total & 37 & & \\
\hline
\end{tabular}

Fonte: Elaborado pela autora

Note que, a amostra se dividiu apenas entre TV $(45,9 \%)$ e Internet $(54,1 \%)$, o que pode ser explicado por terem participantes em sua maioria jovens adultos. Mídias como Rádio, Jornais e Revistas não foram consideradas como forma de acesso a informação. 


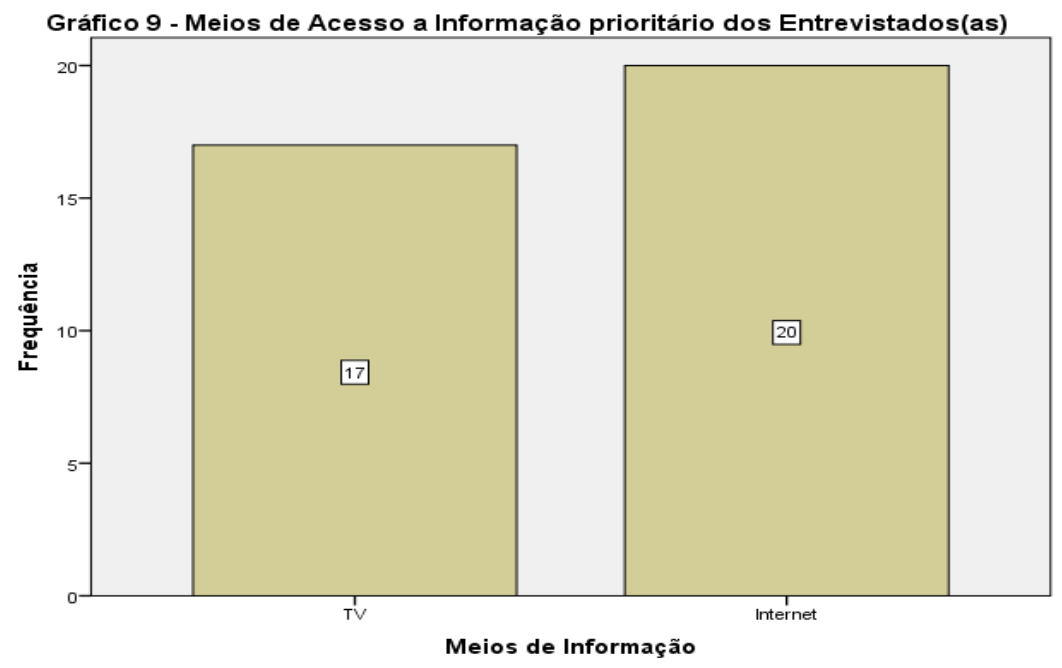

Tabela 10 - Mídia que mais influência em relação a propaganda

\begin{tabular}{|c|c|c|c|c|c|}
\hline & & Frequência & Porcentagem & $\begin{array}{r}\text { Porcentagem } \\
\text { válida } \\
\end{array}$ & $\begin{array}{r}\text { Porcentagem } \\
\text { acumulativa } \\
\end{array}$ \\
\hline \multirow[t]{4}{*}{ Válido } & Internet & 33 & 89,2 & 89,2 & 89,2 \\
\hline & Televisão & 3 & 8,1 & 8,1 & 97,3 \\
\hline & Outra & 1 & 2,7 & 2,7 & 100,0 \\
\hline & Total & 37 & 100,0 & 100,0 & \\
\hline
\end{tabular}

Fonte: Elaborado pela autora

A seguinte Questão 10, buscou identificar qual a mídia mais influenciadora na compra de produtos e serviços. E corroborando com a questão anterior, 89,2\% da amostra afirmam que são influenciados por propaganda disparadas via internet, provavelmente, porque dispensam uma quantidade maior de horas acessando a rede que assistindo TV. Novamente, mídias impressas e rádio nãos constam nas respostas dos participantes (Tabela 10 e Gráfico 10).

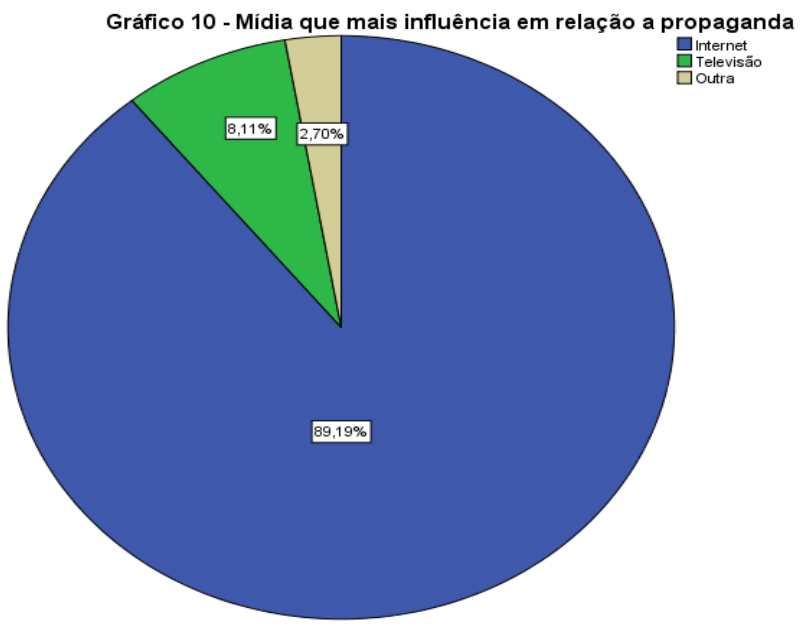


A Questão 11 investigou se existia alguma relação entre a promoção de um produto ou serviço com sua efetiva compra, considerando a dimensão temporal da aquisição. A Tabela 11 e o Gráfico 11 exibem esses dados.

Tabela 11 - Comprou produtos por causa de promoção

\begin{tabular}{|ll|r|r|r|r|}
\hline & & & $\begin{array}{c}\text { Porcentagem } \\
\text { válida }\end{array}$ & $\begin{array}{c}\text { Porcentagem } \\
\text { acumulativa }\end{array}$ \\
\hline Válido & Frequência & Porcentagem & 56,8 & 56,8 & 56,8 \\
& 21 & 24,3 & 24,3 & 81,1 \\
A mais de um ano & 9 & 13,5 & 13,5 & 94,6 \\
A mais de um mês & 5 & 5,4 & 5,4 & 100,0 \\
A um ano & 2 & 100,0 & 100,0 & \\
Total & 37 & &
\end{tabular}

Fonte: Elaborado pela autora

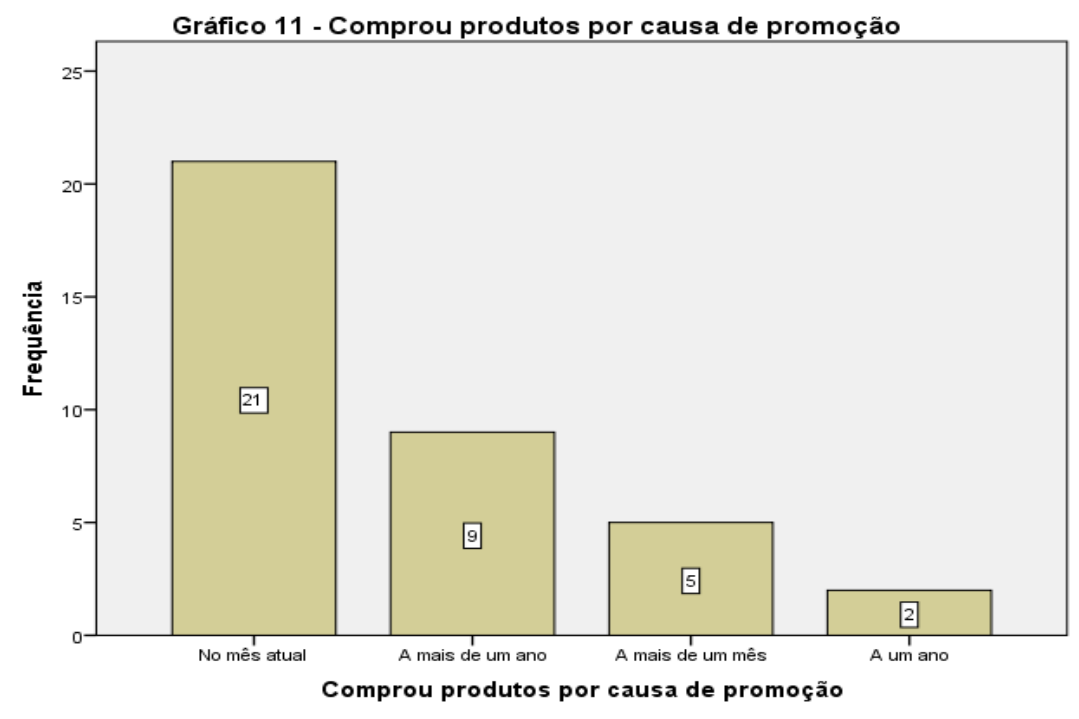

Nota-se que, a maioria dos entrevistados foram influenciados recentemente (mês atual, $56,8 \%$ ). Quase $25 \%$ da amostra já não compra produto ou serviços, influenciados por promoções a mais de um ano. Assim, se estabelecido um corte temporal de até um ano, tem-se 26 participantes que dizem comprar impelidos por promoção dentro de um ano e 11 participantes $(29,7 \%)$ que não adquirem produtos estimulados por promoções a um ano ou mais. 
De forma complementar, a Questão 12 procurou conhecer a probabilidade de o participante adquirir o produto novamente, dado que comprou estimulado pro promoções (Tabela $12 \mathrm{e}$ Gráfico 12).

Tabela 12 - Compraria o produto novamente

\begin{tabular}{|c|c|c|c|c|c|c|c|c|}
\hline & & Frequência & Porcentagem & $\begin{array}{c}\text { Porcentagem } \\
\text { válida }\end{array}$ & \begin{tabular}{|c|} 
Porcentagem \\
acumulativa \\
\end{tabular} & \multirow{2}{*}{\multicolumn{2}{|c|}{$\begin{array}{ll}\text { N } & \text { Válido } \\
\text { Ausen } \\
\text { te }\end{array}$}} & 37 \\
\hline Válido & 1-Muito & 18 & 48,6 & 48,6 & 48,6 & & & 0 \\
\hline & Provavel & & & & & Média & & 1,59 \\
\hline & 2-Provável & 17 & 45,9 & 45,9 & 94,6 & Modo & & \\
\hline & 3-Pouco & 1 & 27 & 27 & 9731 & $D_{0}$ & & \\
\hline & Provável & 1 & $2, r$ & $2, r$ & - & Percent & 25 & 1,00 \\
\hline & 4- & 1 & 2,7 & 2,7 & 100,0 & IS & 50 & 2,00 \\
\hline & Improvavel & & & & & & & \\
\hline & Total & 37 & 100,0 & 100,0 & & & & 2,00 \\
\hline
\end{tabular}

Fonte: Elaborado pela autora

A Tabela 12 traz informações relevantes que permitem explorar as análises dos dados. A moda da amostra é 1 , dos 37 participantes, 18 deles muito provavelmente voltariam a comprar produtos impelidos por promoções, resposta que se repetiu (frequentemente). A média da amostra é igual a 1.59, significando que a média das respostas está entre (1 = Muito Provável e 2 = Provável), com uma pequena tendência para o valor 2, pois verifica-se a ocorrência de duas respostas ( 3 = Pouco Provável) e ( $4=$ Improvável $)$ que pressiona a médica para o valor 4. Assim, $94,6 \%$ da amostra compraria o produto via promoções. O Gráfico 12 ilustra esses dados.

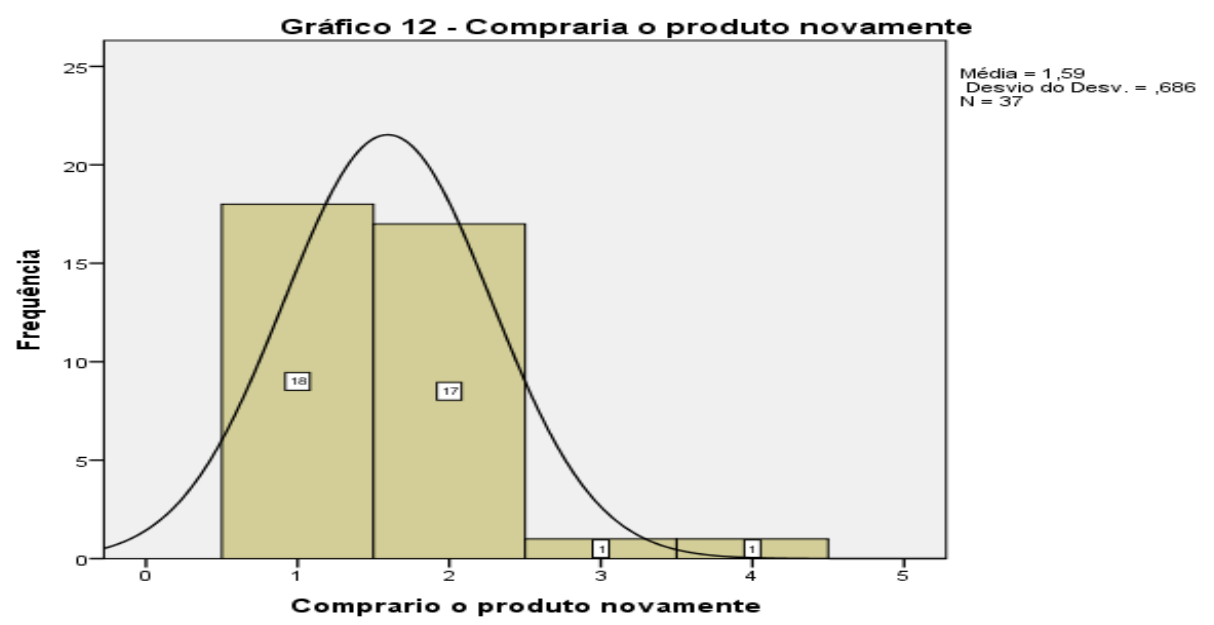


A próxima pergunta questionou se os entrevistados recomendariam o produto adquirido para outras pessoas, ratificando sua decisão acertada de comprá-lo. Os dados referentes a essa questão foram exibidos na Tabela 13 e no Gráfico 13.

\begin{tabular}{|c|c|c|c|c|c|}
\hline & & Frequência & Porcentagem & $\begin{array}{c}\text { Porcentagem } \\
\text { válida }\end{array}$ & $\begin{array}{l}\text { Porcentagem } \\
\text { acumulativa }\end{array}$ \\
\hline \multirow[t]{4}{*}{ Válido } & 1-Muito Provável & 13 & 35,1 & 35,1 & 35,1 \\
\hline & 2-Provável & 23 & 62,2 & 62,2 & 97,3 \\
\hline & 3-Pouco Provável & 1 & 2,7 & 2,7 & 100,0 \\
\hline & Total & 37 & 100,0 & 100,0 & \\
\hline
\end{tabular}

Fonte: Elaborado pela autora

Ratificando a questão anterior, $97,3 \%$ da amostra recomendaria o produto para outras pessoas. Cabe destacar a incidência maior de repostas de 2 = Provável, mudando o valor da moda para 2, e por consequência deslocando a média para a direita, conforme o Gráfico 13.

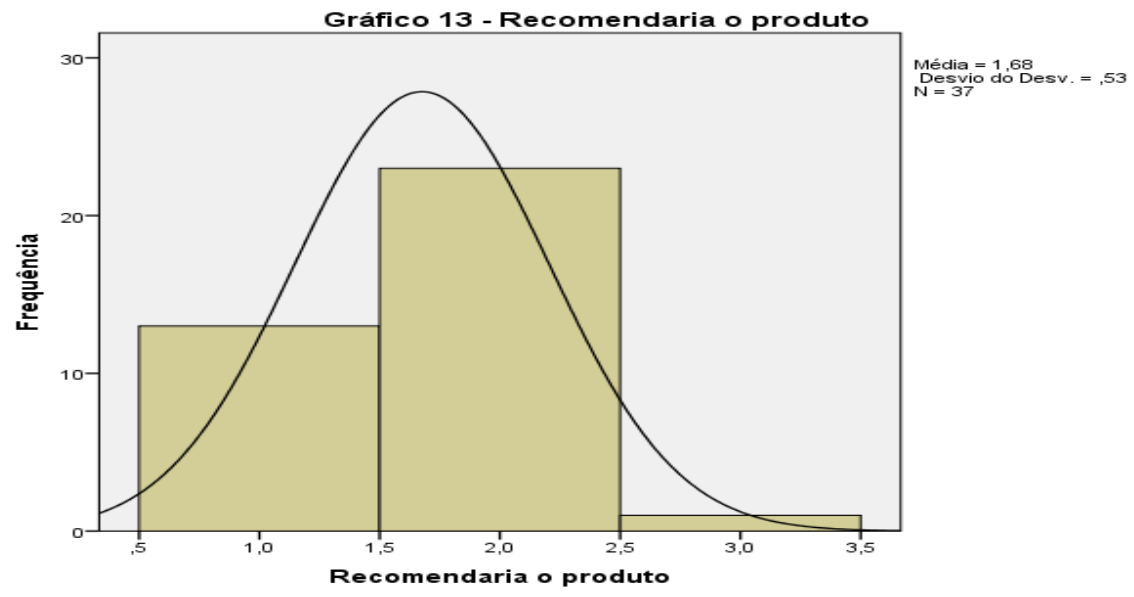

A Questão 14 aborda premissa fundamental de marketing, investigando se a influência direta na compra via propaganda. A Tabela 14 e Gráfico 14 permitem analisar os dados. 
Tabela 14 - Propaganda influenciam na compra de um produto ou serviço

\begin{tabular}{|rl|r|r|r|r|}
\hline & & & $\begin{array}{c}\text { Porcentagem } \\
\text { válida }\end{array}$ & $\begin{array}{c}\text { Porcentagem } \\
\text { acumulativa }\end{array}$ \\
\hline Válido & Frequência & Porcentagem & 67,6 & 67,6 \\
& 25 & 67,6 & 18,9 & 86,5 \\
Não & 7 & 18,9 & 13,5 & 100,0 \\
Não sei & 5 & 13,5 & 100,0 & \\
Total & 37 & 100,0 & & \\
\hline
\end{tabular}

Fonte: Elaborado pela autora

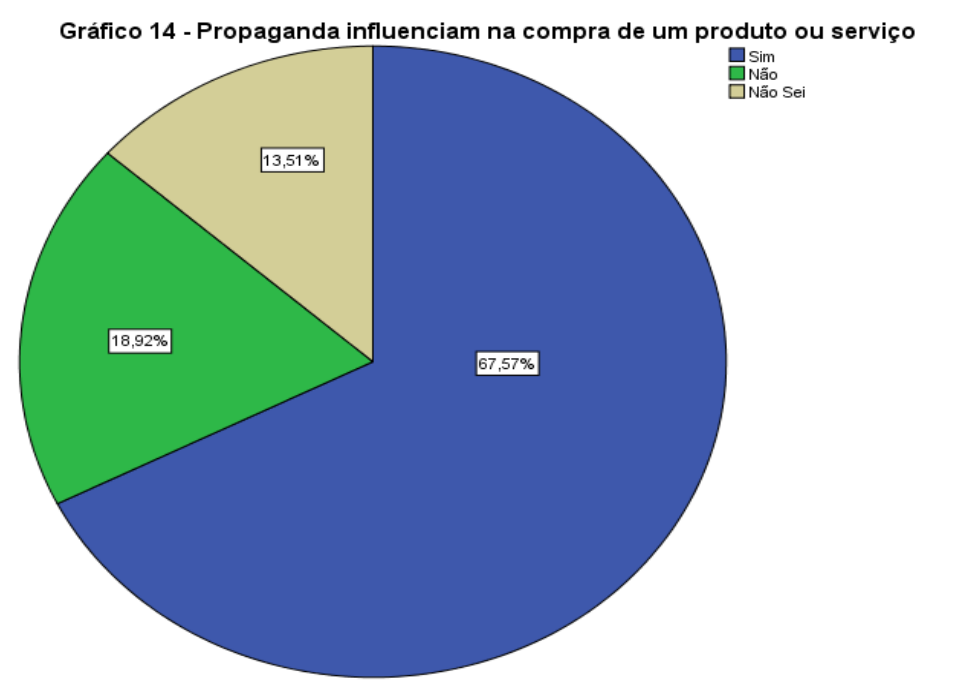

Talvez esse tenha sido o resultado mais óbvio da pesquisa, mas num processo de investigação o objeto seja ratificar ou retificar paradigmas. Neste caso, a maioria dos participantes afirmam serem influenciados pela propaganda.

A Questão 15 tratou de identificar que tipo de produto as propagandas mais influenciam os consumidores a comprar. De acordo com a Tabela 15, 27\% roupas, 27\% eletrônicos, 16,2\% produtos de beleza, $16,2 \%$ alimentos, $10,8 \%$ outros e $2,7 \%$ móveis e eletrodomésticos.

Roupas e eletrônicos perfazem $54,1 \%$, dos produtos que tem seus consumos estimulados por propagandas, de forma especulativa que, atualmente, podem ser adquiridos em grandes lojas de departamentos a preços convidativos. Cabe ressaltar que, a amostra é constituída, em sua maioria, por indivíduos do sexo feminino, jovens e adultas. 
Tabela 15 - Propagandas influenciam a comprar

\begin{tabular}{|ll|r|r|r|r|}
\hline & & & Porcentagem & Porcentagem \\
válida & Frequência & Porcentagem & acumulativa \\
\hline Válido & Roupas & 10 & 27,0 & 27,0 & 27,0 \\
& Eletrônicos & 10 & 27,0 & 27,0 & 54,1 \\
Produtos de beleza & 6 & 16,2 & 16,2 & 70,3 \\
Alimentos & 6 & 16,2 & 16,2 & 86,5 \\
Outro & 4 & 10,8 & 10,8 & 97,3 \\
Móveis e eletrodomésticos & 1 & 2,7 & 2,7 & 100,0 \\
Total & 37 & 100,0 & 100,0 & \\
\hline
\end{tabular}

Fonte: Elaborado pela autora

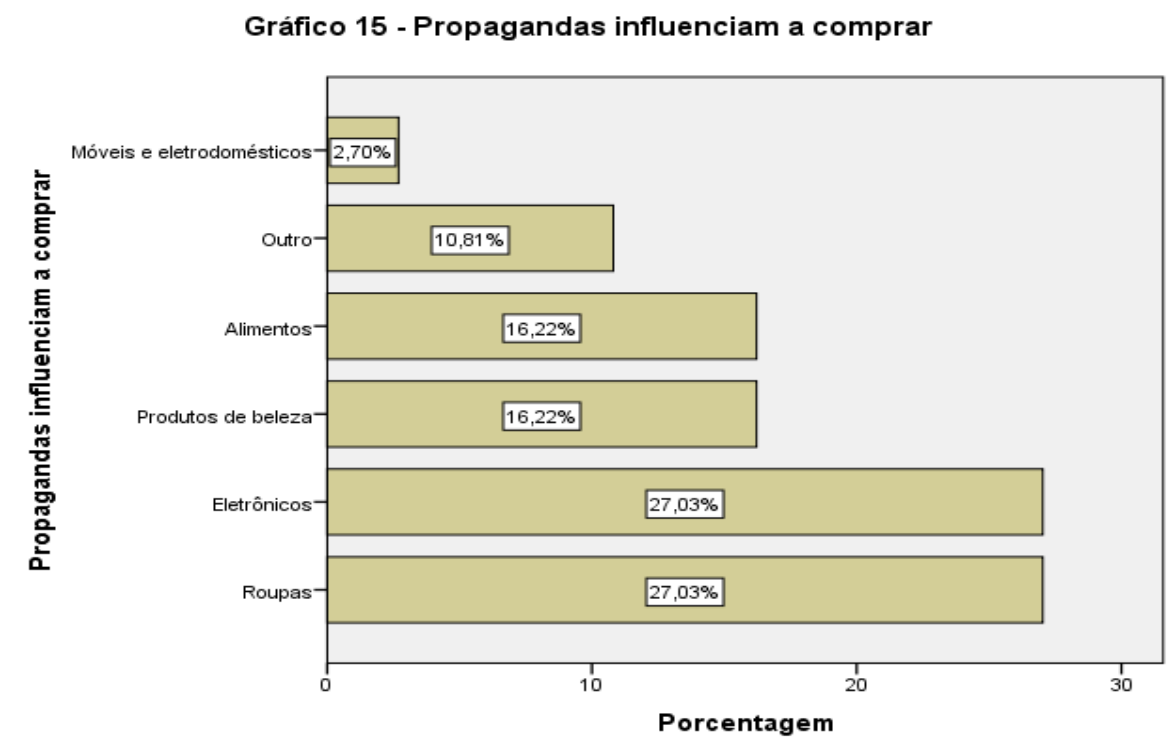

A Questão 16 detectou que tipo de sentimento que as propagandas geram nos respondentes. Verificando os resultados pode-se dizer que trata de um conta censo, em relação a questão anterior. A questão principal abordada foi a propaganda de modo geral, o ato comunicar, não se tratando de direcioná-las a produtos ou serviços específicos. A Tabela 16 mostra que, 43,2\% dos participantes são indiferentes a propagandas genéricas, 37,8\% não souberam definir dentre os três sentimentos, 13,5\% sentem-se seguros com as informações passadas e apenas 5,4\% sentem-se irritados, percentuais quem podem ser vistos no Gráfico 16. 
Tabela 16 - Propagandas causam que sentimento

\begin{tabular}{|rl|r|r|r|r|}
\hline & & & \multicolumn{2}{c|}{$\begin{array}{c}\text { Porcentagem } \\
\text { válida }\end{array}$} & $\begin{array}{c}\text { Porcentagem } \\
\text { acumulativa }\end{array}$ \\
\hline Válido & Frequência & Porcentagem & 43,2 & 43,2 \\
& Indiferença & 16 & 43,2 & 37,8 & 81,1 \\
& Outro & 14 & 37,8 & 13,5 & 94,6 \\
Segurança & 5 & 13,5 & 5,4 & 100,0 \\
Irritação & 2 & 5,4 & 100,0 & \\
Total & 37 & 100,0 & \\
\hline
\end{tabular}

Fonte: Elaborado pela autora

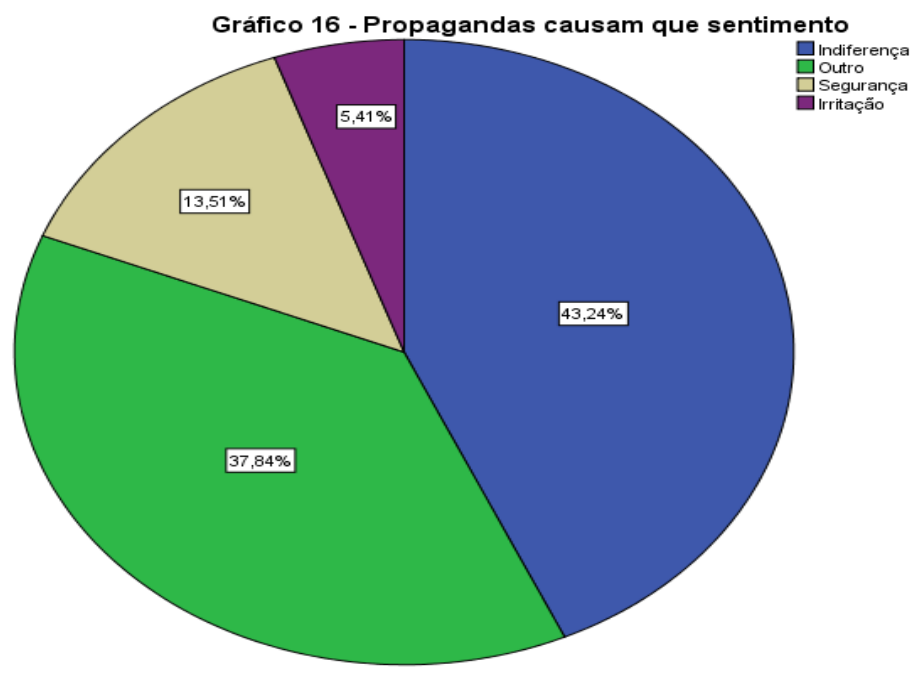

A Questão 17 identificou qual a principal motivação para comprar produtos e serviços.

Tabela 17 - Estimulou a compra do produto/serviço

\begin{tabular}{|ll|r|r|r|r|}
\hline & & & Porcentagem & Porcentagem \\
válida & Frequência & Porcentagem & aculativa \\
\hline Válido & Necessidade de consumo & 26 & 70,3 & 70,3 & 70,3 \\
& Promoções & 6 & 16,2 & 16,2 & 86,5 \\
Benefícios & 4 & 10,8 & 10,8 & 97,3 \\
Outra & 1 & 2,7 & 2,7 & 100,0 \\
Total & 37 & 100,0 & 100,0 & \\
\hline
\end{tabular}

Fonte: Elaborado pela autora

Assim, 70,3\% da mostra afirma que a necessidade pelo produto ou serviço é motivo fundamental para adquiri-lo. Para $16,2 \%$ as promoções levam a adquirir, mesmo sem 
necessidade aparente e 10,8\% foram impelidos por benefícios oriundos da compra (Gráfico17).

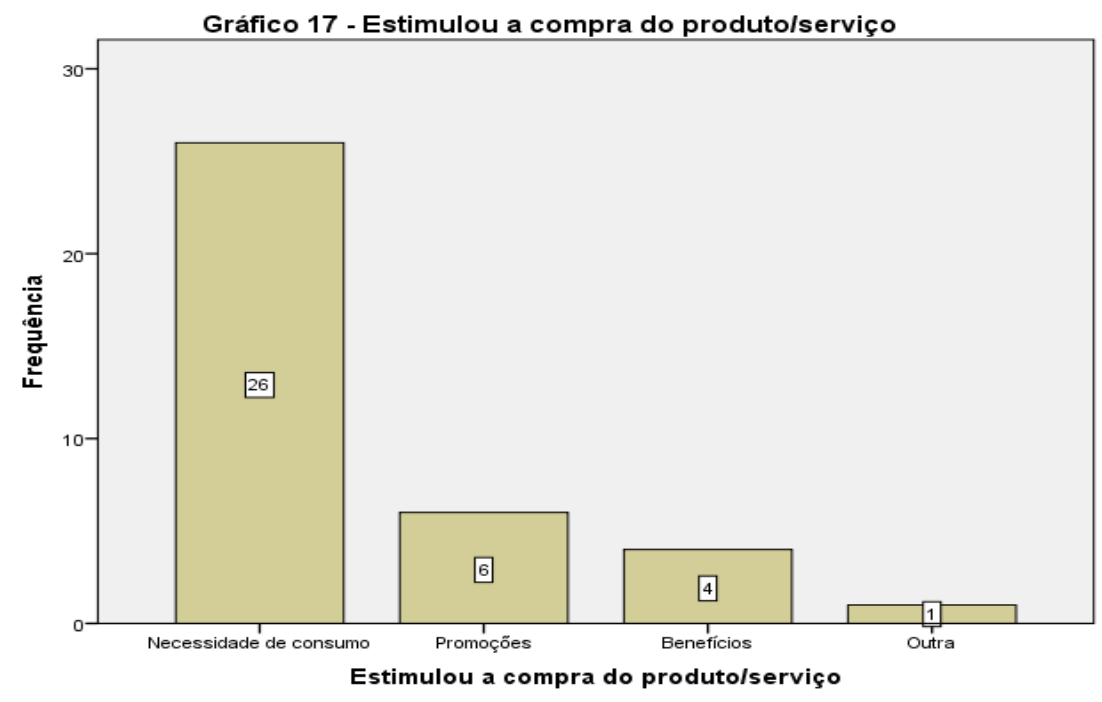

A Questão 18 complementa a questão anterior. Para maioria dos participantes $(64,9 \%)$, as propagandas são vistas como informativas, sem poder de persuasão. Apenas para 16,2\% a comunicação de produtos e serviços convence-as da compra (Tabela 18 e Gráfico18).

Tabela 18 - Percepção sobre as propagandas

\begin{tabular}{|ll|r|r|r|r|}
\hline & & & Porcentagem & Porcentagem \\
válida & acumulativa \\
\hline Válido & Frequência & Porcentagem & 64,9 & 64,9 \\
& Informações sobre o produto & 24 & 64,9 & 16,2 & 81,1 \\
& Convence da necessidade & 6 & 16,2 & 10,8 & 91,9 \\
Outra & 4 & 3 & 8,1 & 100,0 \\
Convence pela aquisição & 37 & 100,0 & 100,0 & \\
Total & 3 & 10,8 & \\
\hline
\end{tabular}

Fonte: Elaborado pela autora

A Questão 19 procurou identificar o grau de satisfação em relação à algumas estratégias utilizadas para promover produtos e serviços. O Quadro 19 sintetiza o processamento dos dados dessa questão. 
Quadro 19 - Satisfação em relação a estratégias de promoção

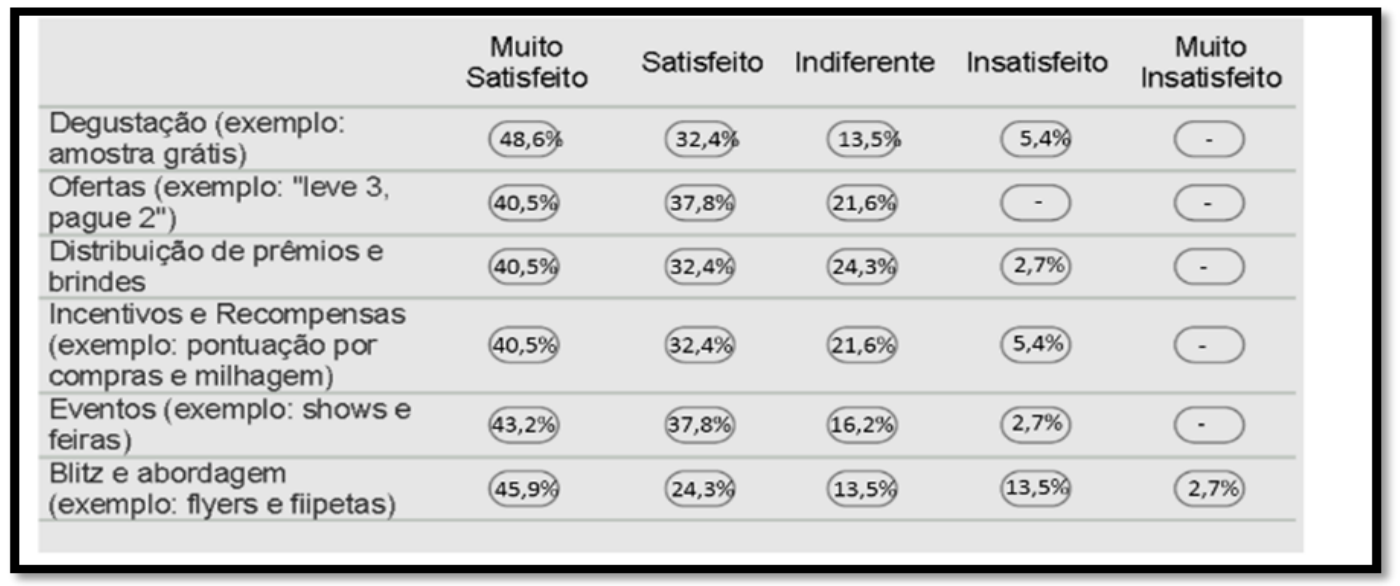

Fonte: Elaborado pela autora

Por fim, a Questão 20 apurou a importância dada pelo participante as estratégias promocionais mostradas no Quadro 19. No sentido de qual delas ele considera a mais importante O resultado é ilustrado pelo Gráfico 19.

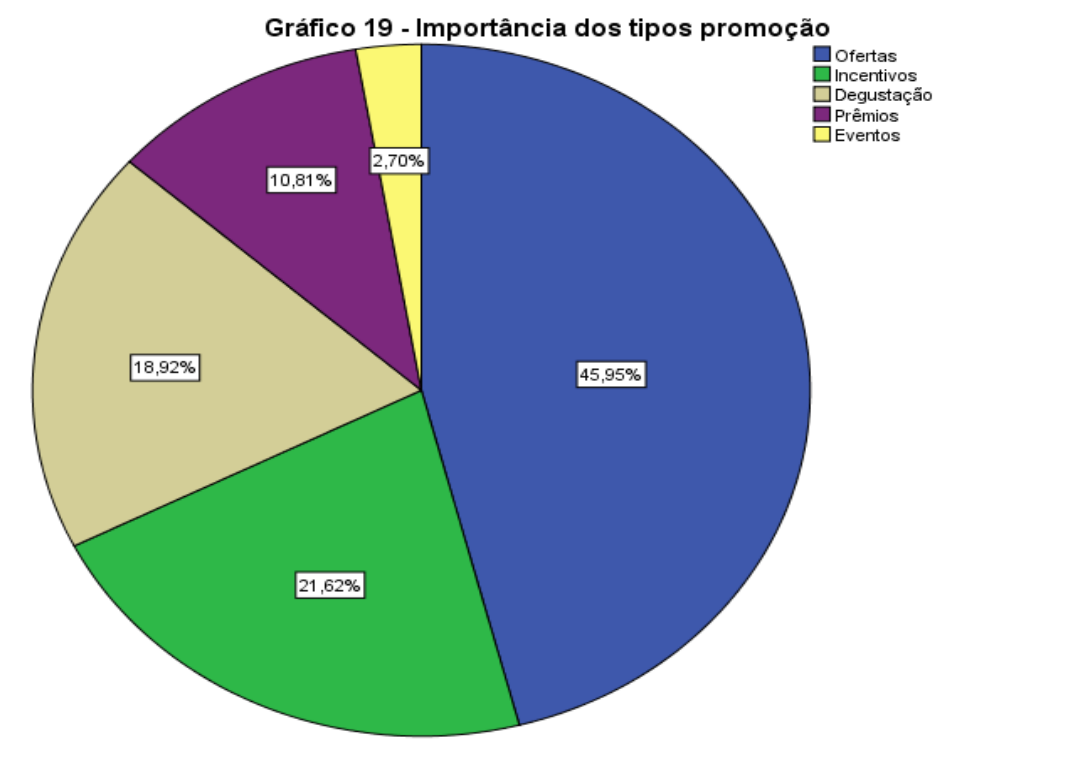

Nota-se que, 45,95\% dão importância maior para ofertas tipo leve 3 e pague 2, 21,56\% para algum tipo de incentivo ou recompensas tipo milhagens, 18,92\% destacam a degustação como fator importante, $10,81 \%$ consideram prêmios e brindes relevantes e $2,70 \%$ acham que eventos como shows e feiras são prioritários. 


\section{Considerações finais}

A amostra é caracterizada fundamentalmente por indivíduos do sexo feminino, com idade entre 26 e 35 anos, solteiras e sem filhos. Com curso superior completo, inserida no mercado de trabalho e com renda familiar entre 4 e 10 salários mínimos.

O objetivo principal do estudo foi verificar a influência da propaganda no processo de tomada de decisão por parte do consumidor. Se considerarmos um corte temporal de até um ano, $81,1 \%$ dos participantes afirmam ter adquirido produtos diretamente influenciados pela promoção, sendo assim, considera-se o objetivo alcançado.

Outro resultado que merece destaque é a mídia que mais influência na compra. Com um percentual de $89,2 \%$ da amostra, a internet tem um papel fundamental no processo de contágio da propaganda na decisão de compra. Isso deve-se ao fato que as pessoas estão cada vez mais conectadas e por passarem uma quantidade maior de horas assistindo televisão, outra mídia que merece destaque nesse contexto.

Por fim, os produtos mais consumidos são igualmente roupas e eletrônicos, aderentes ao perfil da amostra identificada pela pesquisa.

Assim, como recomendação para estudos futuros, pode-se criar substratos da amostra, por exemplo, influência da promoção entre homens casados com filhos em contrastes com homens solteiros sem filhos. Seria perfis de consumidores que gerariam resultados relevantes.

\section{REFERÊNCIAS}

AMPRO. Associação de Marketing Promocional. Disponível em: <http://ampro.com.br/> Acesso em: 17 de out. 2019.

CHURCHILL, Gilbert; PETTER, Paul. Marketing: criando valor para os clientes. 2 ed. São Paulo: Saraiva, 2003.

CRESCITELLI, E. FIGUEIREDO, J. C. B. Ouso de mapas conceituais para ensino de comunicação integrada de marketing. Revista Administração em Diálogo, v.13, n.3, p. 1-24, 2011.

DIAS, Sérgio Roberto. Gestão de Marketing. São Paulo: Saraiva, 2003.

KOTLER, Philip.; ARMSTRONG, G. Princípios de Marketing. São Paulo: Prerntice Hall, 2001.

KOTLER, Philip; KELLER, Kevin L. Marketing Management. 14th Edition, Pearson Education, 2012.

KOTLER, Philip; KELLER Kevin L. Administração de Marketing. A bíblia do marketing. 12 ed. São Paulo: Pearson, 2006.

LAS CASAS, Alexandre Luzzi. Qualidade Total em Serviços: Conceitos, Casos Práticos. 5. Ed. São Paulo: Atlas, 2005. 
LUCAS JR., D.; SOUZA, C. A. Estabelecendo estratégias de comunicação integrada nas redes sociais: análise de uma instituição financeira brasileira. Pensamento \& Realidade, v. 26, n.3, p.45-60, 2011.

OGDEN, J. R.; CRESCITELLI, E. Comunicação Integrada de Marketing: Conceitos, técnicas e práticas. $2^{\mathrm{a}}$ Ed. São Paulo: Prentice Hall, 2007.

OLIVEIRA, E. R.; SERRALVO, F.A.; JOÃO, B. N.; FURLAN, R. M. O Papel da Comunicação Integrada de Marketing na Construção do Valor da Marca: O Caso Bunge Fertilizantes. Revista Organizações em Contexto. V.11, n. 21, p. 127-159, 2015.

SANTOS, G.; FERREIRA, R.; PAIXÃO, M. R. Análise na Aplicabilidade de um Plano de Comunicação Integrada de Marketing (CIM) em um Centro Varejista (Mall). Revista de Tecnologia Aplicada, v.6, n.1, p.48$65,2017$.

SOLOMON, Michael R. Comportamento do Consumidor: Comprando, Possuindo, Sendo. 5a Ed. São Paulo: Bookman, 2002.

VERGARA, Sylvia Constant. Projetos e Relatórios de pesquisa em Administração. 12 Ed. São Paulo: Atlas, 2007.

ZIMMER, P.; REINERT, V. Criando vantagem competitiva na micro e pequena empresa por meio da comunicação integrada em marketing. Revista da Administração da Unimep. v.3, n.2, p. 133-149, 2005.

ZUCCO, F. D.; REIS, C. Comunicação integrada de marketing em eventos turísticos: um estudo da Oktoberfest de Blumenau-SC. Revista Brasileira de Marketing. v.9, n. 3, p. 127-143, 2010. 